Nocturnal Palsy.

It is many years since this condition was described by Dr. Weir Mitchell, but one sees little reference( $\left.{ }^{l}\right)$ to it, though it is not uncommon in neuroses originating in the war. The patient wakes from sleep with his senses fully alert, but unable to move a single voluntary muscle. He is naturally alarmed and makes attempts to move or speak, but without avail, till suddenly with what seems a great effort he regains his power. That he is really awake when in this paralysed state is shown by the unbroken continuity of his sensations of sight and hearing. One of my patients woke in daylight to see a friend in his bedroom. He tried to speak, but could neither speak nor move for some time; when he succeeded in doing so the friend was just as he had previously seen him. The duration of these attacks is variously estimated at from a few seconds to two or three minutes.

The late Dr. Charles Féré, $\left({ }^{2}\right)$ of Bicêtre, recorded a case in which only the right side was paralysed; he says nothing about speech.

P. C. Campbell-Smith.

\title{
4. Treatment of Insanity.
}

The Treatment of the Insane in Pavilions without Detention [Le Traitement des Alienés en "Pavillons Libre"). (Bull. de la Soc. de Med. Ment. de Belg., February, 1922.) Laruelle, L.

The writer's experience shows the need of co-operation between magistrates and alienists. Representations which led to legal in vestigations were made by the former confederates of an alcoholic woman who was improving rapidly in the sanatorium of Fort-Jaco. The inquiry was conducted in a spirit of antagonism and suspicion which spread discontent among patients. The removal either home or to the asylum was ordered of certain patients well suited to sanatorium care who had not asked to go. These included chronic psychoses without anti-social conduct, paranoias, simple dementias, transitory and curable psychoses, etc. In particular the removal home as mentally fit and wishing to leave was ordered of a blind paraphrenic who made a stereotyped demand for discharge to go to " $\mathrm{X}$, where she had the freedom of the city," but who remained, though she carried the writer's signed permit, and who refused to depart with her friends. Other cases, unable to exercise volition (e.g., of stupor) were to be certified.

These events raise wider issues. For twenty years the writer has conducted, with magisterial approval, an open sanatorium outside the Asylum at Liege for patients either throughout their illness or before or after asylum treatment. Experience teaches that such institutions increase curability, shorten the duration of psychoses, prevent psychic contamination and morbid imitation and lessen the frequency of certification. Yet apparently these and even open wards in asylums are against Belgian law, which allows only home

(1) "Deuxième note sur la fausse réminiscence," Gourn. de Neurol., Bruxelles, about 1905.- $\left({ }^{2}\right)$ "Les crampes et les paralysies nocturnes," La Médecine Moderne, 1900, Dr. C. Féré. 
or asylum treatment. A reaction towards stricter legal enforcement threatens the many existing institutions and kills progress. Is illegal detention of a sane man-that man constantly mentioned and never found-more socially menacing than cases of incipient insanity, constitutional psychopathic disorder, drug addiction, curable insanities, harmless manias and mental infirmities? The writer demands relief from his dilemma of being either a bad citizen contravening the law, or a bad physician withholding from his patients treatment in the spirit of contemporary medicine. The Société de Médecine Mentale de Belgique, which has long advocated improved organisations for neuro-psychopathic diseases, should urge both toleration and changes in the law. Confinement in asylums should be exceptional. Sanatoria should be scientific, should have the responsible physician resident and equal to asylum status, and be inspected sympathetically by a medical body available also for consultation. The patient's material interests should be protected by legal authority.

Marjorie E. FrankLin.

A Plea for more Accurate Diagnosis and Intensive Treatment of Syphilis

in State Institutions. (State Hosp. Quart., August, 1921.) Ross, F. R.

This plea for greater use of the opportunities which hospital control affords for the diagnosis and treatment of syphilis is based on replies to a questionnaire sent to institutions for the insane and mental defectives in U.S.A. and Canada, and on personal experience as superintendent of Dannemora State Hospital. At Dannemora, of syphilitic cases which received adequate treatment (limited by expense to 25 per cent.), with the exception of paretics, all responded by changes in the Wassermann reaction of blood and spinal fluid and by physical improvement, and nearly all by mental improvement, usually preceded by temporary loss of weight and occasionally by transitory mental exacerbations. Reports of four cases are given as examples. Treatment, the details of which are described, consisted in four courses of neo-arsphenamide given intravenously combined with mercury salicylate intramuscularly and sodium iodide by mouth, and with attention to diet and hygiene. Some paretics showed reductions in Wassermann, blood-count and globulin, but not in gold curve, nor has there, as yet, been a cure. General paralysis, however, is simulated by curable forms of neuro-syphilis. Syphilis may be a factor leading to loss of mental balance even without actual cerebral infection. A routine Wassermann test should be made on all inmates, and all serologically or clinically syphilitic should receive intensive treatment. MARJORIE E. FRANKLIN.

Training Aides for Mental Patients. (Arch. of Occupat. Ther., February, 1922.) Slagle, Eleonor $C$.

Emphasis should be laid on the relation of directed activity to mental adjustment and social rehabilitation. There are three groups to be dealt with : (a) Patients likely to remain permanently in hospital, 